\title{
New Record of the Leopard Gecko Goniurosaurus araneus (Squamata: Eublepharidae) for China and Habitat Partitioning between Geographically and Phylogenetically Close Leopard Geckos
}

Tian-Bo Chen ${ }^{1}$, Yuan-Jun Meng ${ }^{1}$, Ke Jiang ${ }^{2,3}$, Pi-Peng Li ${ }^{3}$, Bo-Hao Wen ${ }^{4}$, Wenhua Lư ${ }^{5}$ James Lazell ${ }^{5}$, and Mian Hou ${ }^{3,6}$

${ }^{1}$ Nonggang National Natural Reserve, Chongzuo, Guangxi 532412, China

${ }^{2}$ State Key Laboratory of Genetic Resources and Evolution, Kunming Institute of Zoology, Chinese Academy of Sciences, Kunming, Yunnan 650223, China ${ }^{3}$ Institute of Herpetology, Shenyang Normal University, Shenyang, Liaoning 110034, China

${ }^{4}$ Kadoorie Farm and Botanic Garden, New Territories, Hong Kong, China

${ }^{5}$ The Conservation Agency, 6 Swinburne Street, Jamestown, Rhode Island 02835, USA

${ }^{6}$ Academy of Continuing Education, Sichuan Normal University, Chengdu, Sichuan 610068, China (turtlechina@126.com)

\begin{abstract}
Two specimens of the Leopard Gecko Goniurosaurus araneus (Squamata: Eublepharidae) were collected from Nonggang National Nature Reserve, Chongzuo Prefecture, Guangxi Zhuang Ethnicity Autonomous Region, China, in October 2011. This species is a new record for China and this report is a range extension for the species from northern Vietnam to southern Guangxi. A phylogenetic study demonstrated that Goniurosaurus araneus and G. luii are a species pair. We show for the first time that they coexist broadly but are narrowly allopatric in a small area in southern Guangxi, separated only by a river, similar to what had been reported previously for G. yingdeensis and Goniurosaurus indet. from northwestern Guangdong. A river as a geographical barrier, elevation, and aspect may have contributed to habitat partitioning between $G$. araneus and $G$. luii.
\end{abstract}

Key words: Goniurosaurus luii, distribution, separation by river, geographic barrier, elevation, aspect, karst, Nonggang

\section{Introduction}

Leopard Geckos of the genus Goniurosaurus are distributed exclusively in karst and igneous substrate forests in eastern and southeastern Asia. Areas include the Ryukyu Archipelago, South China (Hainan, Guangdong, Guangxi, and Guizhou Provinces), and northern Vietnam. Nonggang National Nature Reserve (NNR) in southern Guangxi (Fig. 1), a province designated as the Autonomous Region for the Zhuang minority people in China, covers an area of more than 100 $\mathrm{km}^{2}$, including $73 \mathrm{~km}^{2}$ of primary tropical rainforest, all on karst landform. Elevation ranges from 100 to $600 \mathrm{~m}$ above sea level, with a mean annual temperature of $22^{\circ} \mathrm{C}$ and mean annual rainfall of 1,350 mm (Qi 1980). Eighty-eight species of amphibians and reptiles, including $G$. luii, have been recorded (Yang et al. 2011). During a field trip in October 2011, we collected two individual Goniurosaurus, which we herein assign to G. araneus Grismer, Viets, and Boyle, 1999, and, for the first time, report a range extension of this Leopard Gecko from northern Vietnam to southern China as a new record for China. We also confirm the presence of $G$. luii in Nonggang.

The distributions of $G$. araneus and $G$. luii are intertwined with $G$. hainanensis and $G$. lichtenfelderi and rather perplexing, prompting a review of the history of Goniurosaurus. Mocquard (1897) described the first species, Eublepharis lichtenfelderi, from two specimens from Grande Norway Island (Xuy Nong Chao) in the Tonkin Gulf, northern Vietnam (Fig. 1). Barbour (1908) first established the genus Goniurosaurus, based on a new species, G. hainanensis, from a single specimen collected from Mt. Wuchi (Wuzhishan, Five Finger Mountain), central Hainan Island, China. Namiye (1912) described Gymnodactylus albofasciatus kuroiwae from the Ryukyu Archipelago; Wermuth (1965) separated them and moved the subspecies to Goniurosaurus as G. kuroiwae; the former is now Geckoella albofasciatus 
(Boulenger, 1885). Maki (1931) described Eublepharis orientalis from Tonakishima and Tokashiki Islands; Okada (1936) described Gymnodactylus yamashinae from Kumejima
Island; Nakamura et al. (1959) described Eublepharis splendens from Tokunoshima Island; all three also occur on the Ryukyu Archipelago. Börner (1981) created a new genus

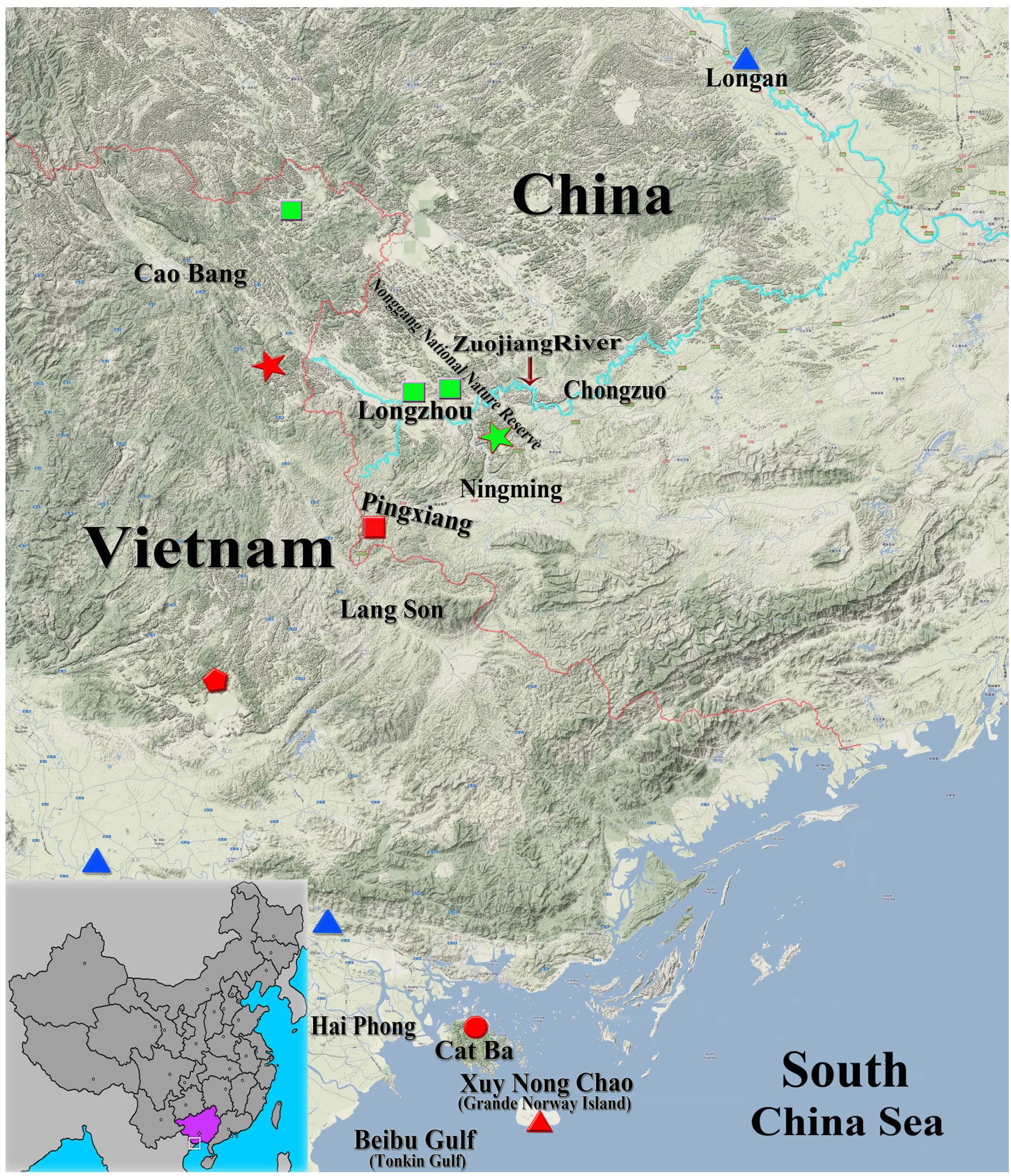

Fig. 1. Distribution map of Goniurosaurus species between northern Vietnam and southern Guangxi, with stars for G. araneus, circles for G. catbaensis, pentagons for $G$. huuliensis, triangles for $G$. lichtenfelderi, rectangles for $G$. luii (all type localities in red), and the courses of rivers in sky blue. 
Amamisaurus to include all these four species. Grismer (1987) corrected this move and placed all Leopard Geckos from the Ryukyu Archipelago, southern China, and northern Vietnam in Goniurosaurus.

The last 20 years have been the most active period in the discovery of additional species of Goniurosaurus. Grismer et al. (1994) described G. kuroiwae toyamai from Iheyajima Island; Dickhoff (2004) elevated that taxon to a species as G. toyamai, resulting in a total of five species known from the Ryukyu Archipelago thus far. Grismer et al. (1999) described two species, $G$. araneus and $G$. luii, from near the border between Vietnam and China in Cao Bang and Guangxi Provinces, respectively (Fig. 1). Grismer et al. (2002) described G. bawanglingensis from Bawangling NNR on Hainan Island, China. Orlov et al. (2008) described $G$. huuliensis from Lang Son Province, northern Vietnam (Fig. 1). Ziegler et al. (2008) described G. catbaensis from Cat Ba Island in the Tonkin Gulf, northern Vietnam (Fig. 1). Wang et al. (2010) described G. yingdeensis from Shimentai NNR in Yingde County, Guangdong Province, China; at the same time, Yi et al. (2010) reported another form, Goniurosaurus indet., from nearby Qingxin County. Wang et al. (2013) described G. liboensis from Maolan NNR in Libo County, Guizhou Province, China. The genus currently contains 15 known species.

No one paid attention to $G$. hainanensis since its original description in 1908 until Smith (1935) regarded it as a synonym of $G$. lichtenfelderi. Huang (1964) then reported an Indian species, Eublepharis macularius (Blyth 1855), based on two specimens from Dongfang County, Hainan Island. Grismer (1988) regarded this report near the type locality of $G$. hainanensis as a mistake for a species close to G. lichtenfelderi, and further provided evidence that $G$. hainanensis and G. lichtenfelderi were geographic subspecies. In that same year, Hu and Zhao (1987) regarded G. hainanensis as $G$. lichtenfelderi by listing $G$. lichtenfelderi from Hainan as the only Leopard Gecko for China. Their work provided the first Hainan appearance for $G$. lichtenfelderi. Adding to the confusion, Li et al. (1986) reported G. lichtenfelderi from Guizhou; this different species was then treated as such in the literature until Wang et al. (2013) found more specimens and identified them as G. liboensis, thus excluding G. lichtenfelderi from Guizhou. Orlov and Darevsky (1999) described G. murphyi from a village between Bac Ninh and Bac Giang Provinces (Fig. 1), but Grismer (2000) regarded it as a junior synonym of $G$. lichtenfelderi, making it the first continental record from northern Vietnam after more than 100 years since its first description from an island. At the same time, G. hainanensis was elevated to a species and its distribution was defined as restricted to Hainan Island (Grismer 2000, Blair et al. 2009). A historical report of $G$. lichtenfelderi by Wen (1983) from Longan County, near Nanning, southern Guangxi (Fig. 1) is the likely source of the record for G. lichtenfelderi from Guangxi in Zhao and Adler (1993). Because of the close proximity of the Vietnamese continental locality to Guangxi, we have included this single record of $G$. lichtenfelderi for China until the specific locality is revisited. However, we herein disregard the record of $G$. lichtenfelderi from Guangdong in $\mathrm{Li}$ et al. (2011) because it was based on Goniurosaurus indet. (Yi et al. 2010), which definitely is a distinct species that is similar to G. yingdeensis in at least the number of body bands. Consequently, the distribution of G. lichtenfelderi is from a mainland locality in southern Guangxi, the holotypic island in the Tonkin Gulf, and a mainland locality in northern Vietnam (Fig. 1). Grismer et al. (1999) mentioned G. luii from Hainan based on two specimens from pet markets but dismissed this record in Seufer et al. (2005), resulting in the distribution of $G$. luii being only from Guangxi. However, Thanh et al. (2006) reported G. luii from northern Vietnam (Fig. 1), creating a broad distribution of the species across the international border. Although Grismer et al. (1999) referred to $\mathrm{Hu}$ and Zhao (1987) for the distribution of G. araneus, thus implying its presence in China, that work contains no mention of $G$. araneus. Perhaps they treated the listing of $G$. lichtenfelderi in Vietnam by $\mathrm{Hu}$ and Zhao (1987) as G. araneus or it might have been a mistranslation of the listing or the citation.

In summary, only seven species of Goniurosaurus were recorded from China: G. bawanglingensis (Hainan), G. hainanensis (Hainan), G. liboensis (Guizhou), G. lichtenfelderi (Guangxi), G. luii (Guangxi), G. yingdeensis (Guangdong), and Goniurosaurus indet. (Guangdong). This report of G. araneus increases the number of species or forms in Goniurosaurus from seven to eight in China.

Coexistence of $G$. araneus and $G$. luii within a small area like Nonggang caught our attention. A similar phenomenon was first observed for G. yingdeensis and Goniurosaurus indet. in northwestern Guangdong, with only a river separating the pair (Zhang et al. 2014). We herein provide preliminary data on habitat partitioning between $G$. araneus and $G$. luii from Nonggang, morphological variation, and comparisons among species of Leopard Geckos. This paper also provides specific locality records of $G$. luii in order to define its distribution beyond the type locality in China.

\section{Materials and Methods}

Tian-Bo Chen collected two adult specimens of $G$. araneus (KIZ-012729 and KIZ-012730) from Nonggang NNR $\left(22^{\circ} 29^{\prime} 38^{\prime} \mathrm{N}, 106^{\circ} 47^{\prime} 06^{\prime} \mathrm{E}\right)$, Longzhou County, Chongzuo Prefecture, Guangxi Zhuang Ethnicity Autonomous Region, China, at night in October 2011. A total of four specimens of $G$. luii also were collected from the same reserve and time frame but in different localities (NG-11101503, 11101508, $11102125,11102202)$. These specimens were compared 
with Chinese and Vietnamese congeners and other currently undescribed Chinese species from the wild, pet markets, and/ or photos and descriptions in literature. They were fixed in $75 \%$ ethanol (after preserving liver tissues in 95\% ethanol for DNA analysis) and deposited in the Kunming Institute of Zoology (KIZ), Chinese Academy of Sciences, Kunming, Yunnan Province, China. We subsequently examined habitat parameters for these localities, including elevation, plant composition, and aspect.

All measurements were made with an electronic vernier caliper to the nearest millimeter. Measurable and meristic abbreviations are as follows: snout-vent length (SVL), tail length from posterior edge of the vent to the tip of the tail (TAL), snout to eye length from the tip of the snout to the anterior-most point of the eye (SEL), maximum inter-orbital distance (IOD), eye to ear distance from the posterior margin of the eye to the posterior margin of the ear (EE), maximum head width (HW), head length from the tip of the snout to the posterior margin of the ear (HL), maximum head height $(\mathrm{HH})$, forelimb length from the axilla to the tip of the fourth finger (FLL), hindlimb length from the groin to the tip of the fourth toe (HLL), number of supralabials (SL), number of infralabials (IL), number of nasal scales surrounding the nares $(\mathrm{N})$, number of internasals (IN), number of ciliaria (CIL), number of postmentals (PM), number of gular scales bordering the postmentals (GP), number of dorsal tubercle rows at midbody (DTR), number of granular scales surrounding the dorsal tubercles (GST), number of paravertebral tubercles between limb insertions (TL), number of scales around midbody (MB), number of subdigital lamellae on the forelimb under the first to fifth fingers (LD1, LD2, LD3, LD4, LD5), number of subdigital lamellae on the hindlimb under the first to fifth toes (LT1, LT2, LT3, LT4, LT5), number of preanal pores (PP), number of postcloacal tubercles (PAT), and number of dorsal tubercles in the first, fourth, and eighth caudal whorls (DT1, DT4, DT8). Bilateral scale counts are given as right/left.

\section{Results}

Habitat partitioning.-Goniurosaurus araneus is currently known only from the type locality in Vietnam and Nonggang NNR, Guangxi, China. It is nocturnally active in karst brae covered with thick tropical rainforest (Fig. 2). The two specimens were collected in the Longshan area at elevations of $150-170 \mathrm{~m}$. The four individuals of $G$. luii in Nonggang NNR also were nocturnally active in karst brae and collected at elevations of 180-260 m. The habitat of the two species was separated by the Zuojiang River (western river in Fig. 1), running approximately northwest to southeast from Vietnam to Nonggang, then from west to east to meet with the Youjiang River (eastern river) after Nonggang (Fig. 1); these two rivers join to form the Yongjiang River, a major tributary in the Pearl River drainage system. Extensive sur-

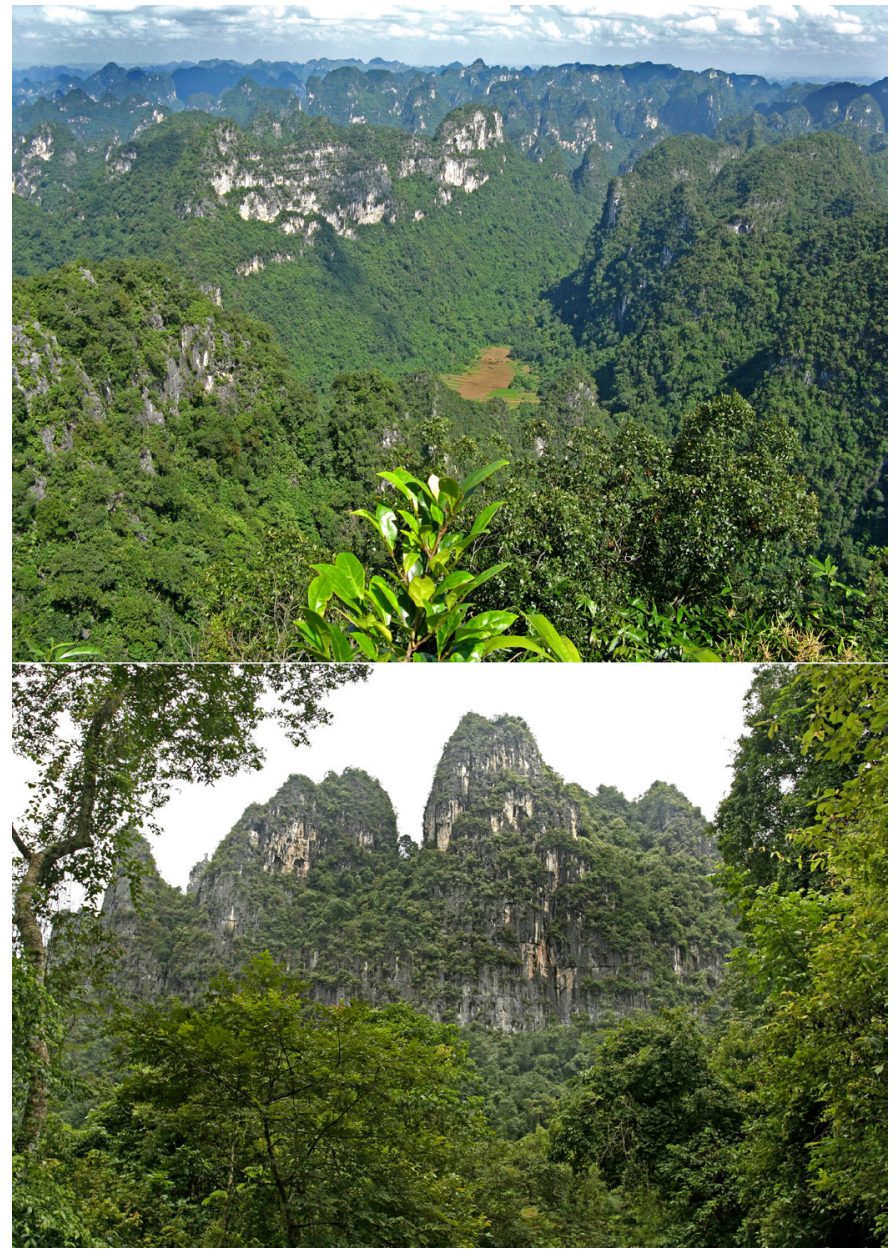

Fig. 2. Habitats of Goniurosaurus araneus and G. luii at Nonggang National Nature Reserve, southern Guangxi, China. Photographs by Tian-Bo Chen.

veys since 2009 confirmed that the species were allopatric and that their ranges were separated by the river. The area northeast of the Zuojiang River was occupied by G. luii and that to the southwest by $G$. araneus. Both species were active at night mostly on rock surfaces and occasionally on the forest floor. The principal vegetation at the respective elevations did not appear to differ in canopy height or plant composition; however, the aspects where two species were found differed, $G$. araneus frequently on north-facing slopes, $G$. luii on south-facing slopes. The two individuals of $G$. araneus were fed crickets, scalewings (Lepidoptera), spiders, small beetles (Tenebrionidae), and waxworms (Pyralidae) in captivity near the site of collection.

Morphological variation.-The diagnostic characters of G. araneus from Nonggang are: Nuchal loop and four body bands between the forelimb insertion and the caudal constriction are broad, pale to bright orange; five caudal bands are white; body and limbs are nearly immaculate dorsally and laterally with only a few spots; males have 23-29 preanal pores. In life, the dorsal ground color of head and body was rusty brown 
with a bluish gray tint (Fig. 3A), that of limbs more purplish; a few individuals from pet markets had more or larger speck- les (Fig. 3B-D), calvaria mottled with some large dark spots or irregular blotches, and an orange-brown iris. The nuchal
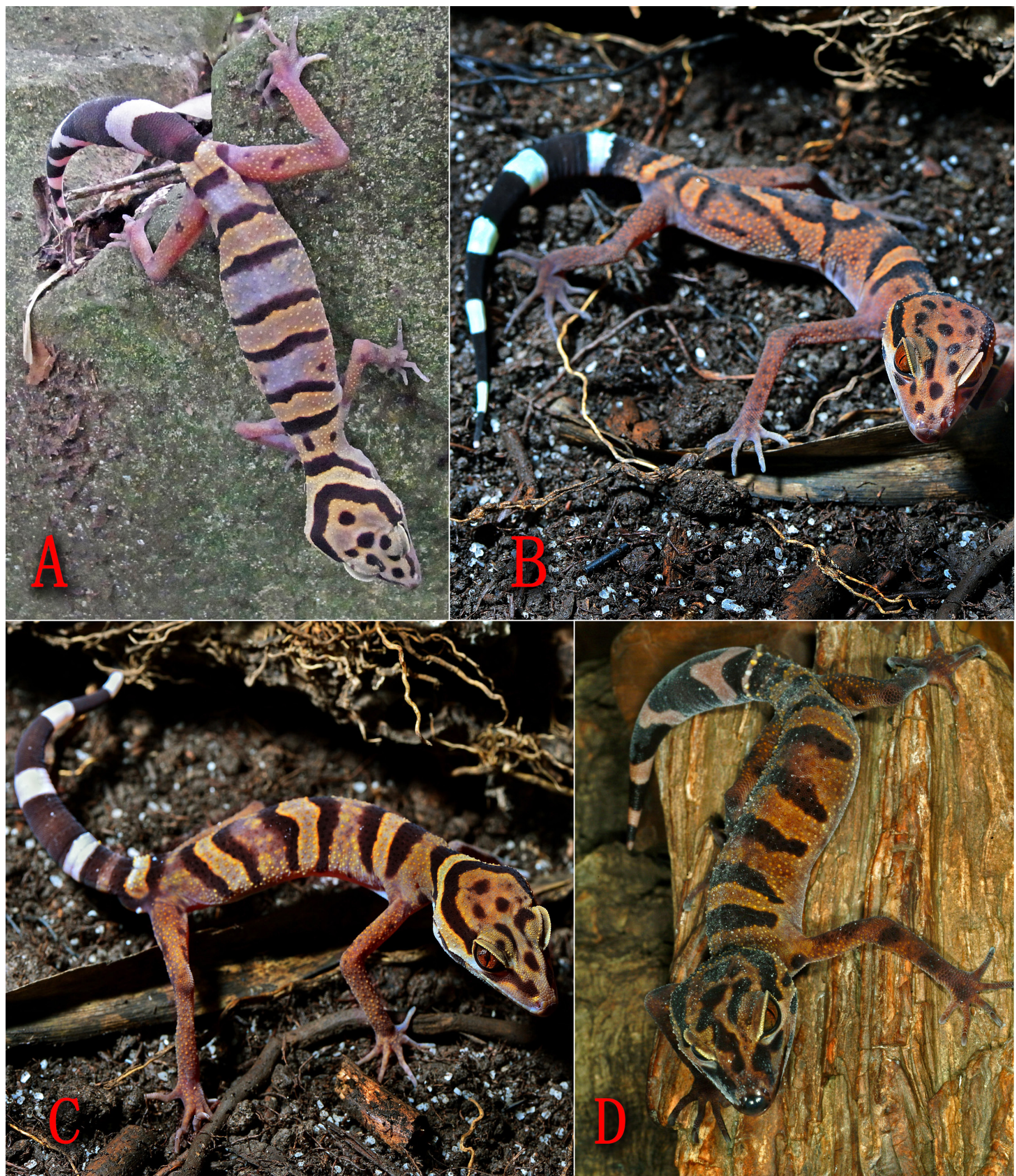

Fig. 3. Variation among live Goniurosaurus araneus in head marking, body bands, dorsal and lateral mottling, and tail (A, female KIZ-012730 with regenerated tail and few dark spots on head; B, pet market female with original tail, unusual body bands, and numerous dark spots on head; C, pet market male with original tail and few dark spots on head; D, male with regenerated tail and large dark blotches on head). Photographs by Tian-Bo Chen (A), Hang Yang (B, C), and Nikolai L. Orlov (D). 
loop and body bands were edged anteriorly and posteriorly with black; all orange bands were immaculate. The ground color of the tail was black to dark brown; white caudal bands were immaculate and complete ventrally. Ventral surfaces of the head, body, and limbs were dull white. In ethanol (Fig. 4 ), the ground color of the dorsum became gray; the nuchal loop and body bands turned pale white, but spots and edges of body bands remained darker than the interspaces; the
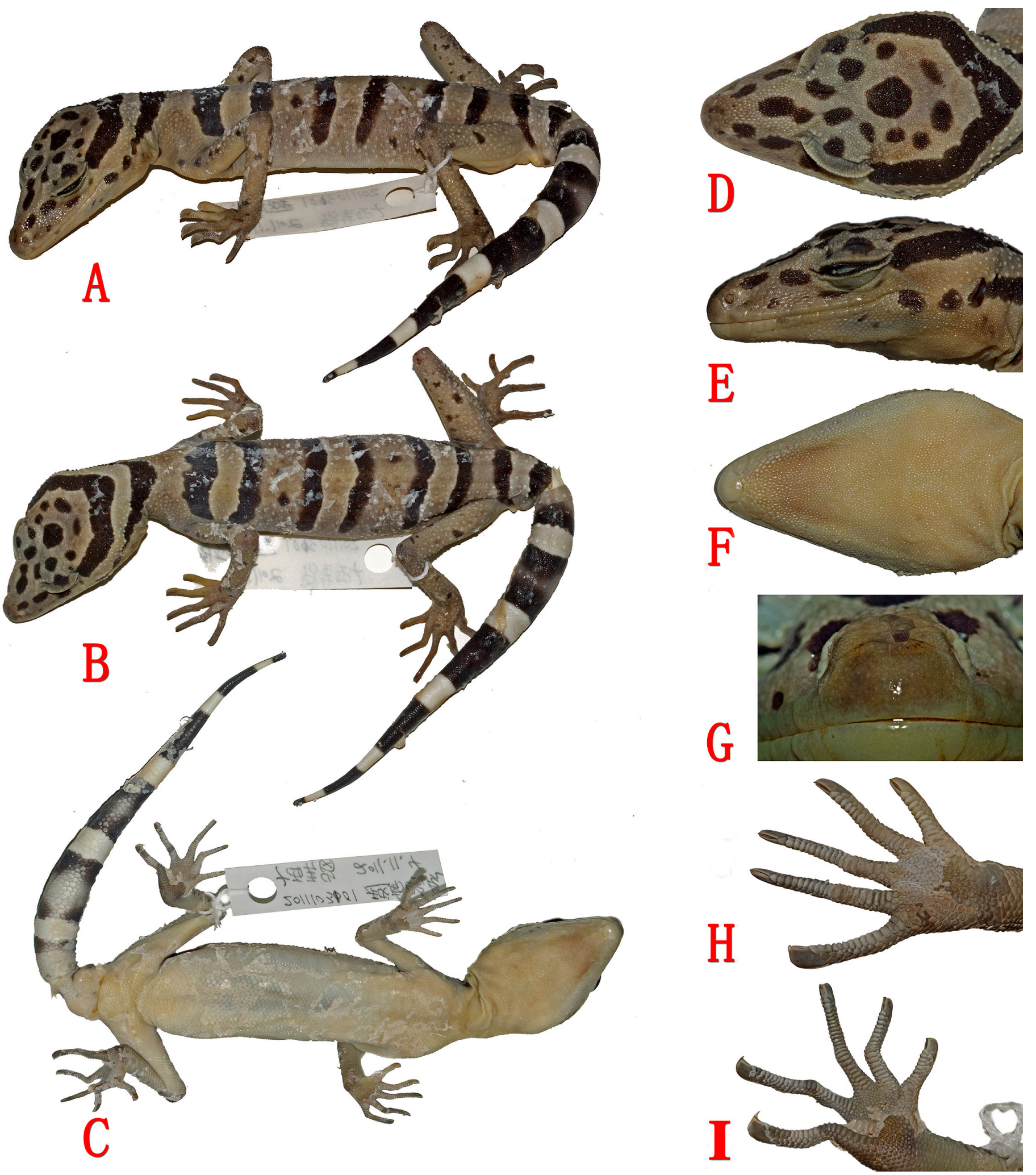

Fig. 4. Goniurosaurus araneus (KIZ-012729 in ethanol) in lateral, dorsal, and ventral full views (A, B, C, respectively), its head in dorsal, lateral, and ventral views (D, E, F, respectively), rostral and mental scales $(G)$, and ventral pes and manus (H, I). Photographs by Mian Hou. 
white caudal bands lost the bluish tint. Morphological measurements are detailed in Table 1.

Of the two individuals from the Nonggang NNR, the male has a pair of internasal scales between the first supranasals, but the female has only one (Fig. 5A-B). We also checked specimens from pet markets and literature records; most individuals have only one internasal contacting the midline behind the rostral. The transverse series of caudal tubercles on the original tail is absent on the regenerated tail (Fig. 5C-D). In the male, a distinct enlarged globular region was evident between the posterior edge of the cloaca and the base of the tail (Fig. 6A), as opposed to the lack thereof in the female (Fig. 6B). Preanal pores were distinctly present only in males (Fig. 6C) and absent in females (Fig. 6D).

Grismer et al. (1999) noted the absence of a row of enlarged supraorbital tubercles in $G$. araneus, but rows were present in both specimens (Fig. 7). The counts of eyelid fringe scales were lower than those given by Grismer et al. (1999; 52-54 versus 61-67) and the body scales of $G$. araneus from Nonggang were more granular than elongate as described by Grismer et al. (1999).

Species comparisons._-Goniurosaurus araneus (Fig. 8A-B) differs mainly from G. hainanensis (Fig. 8L) and G. lichtenfelderi (Fig. $8 \mathrm{~K})$ in the number of body bands between the forelimb insertion and caudal constriction, as well as in the number of preanal pores. Goniurosaurus araneus has four body bands and 23-29 (erroneously reported as 18-22 in Wang et al. 2013) preanal pores, whereas the latter two species both have only three body bands. Goniurosaurus hainanensis (24-32; Grismer et al. 2002,

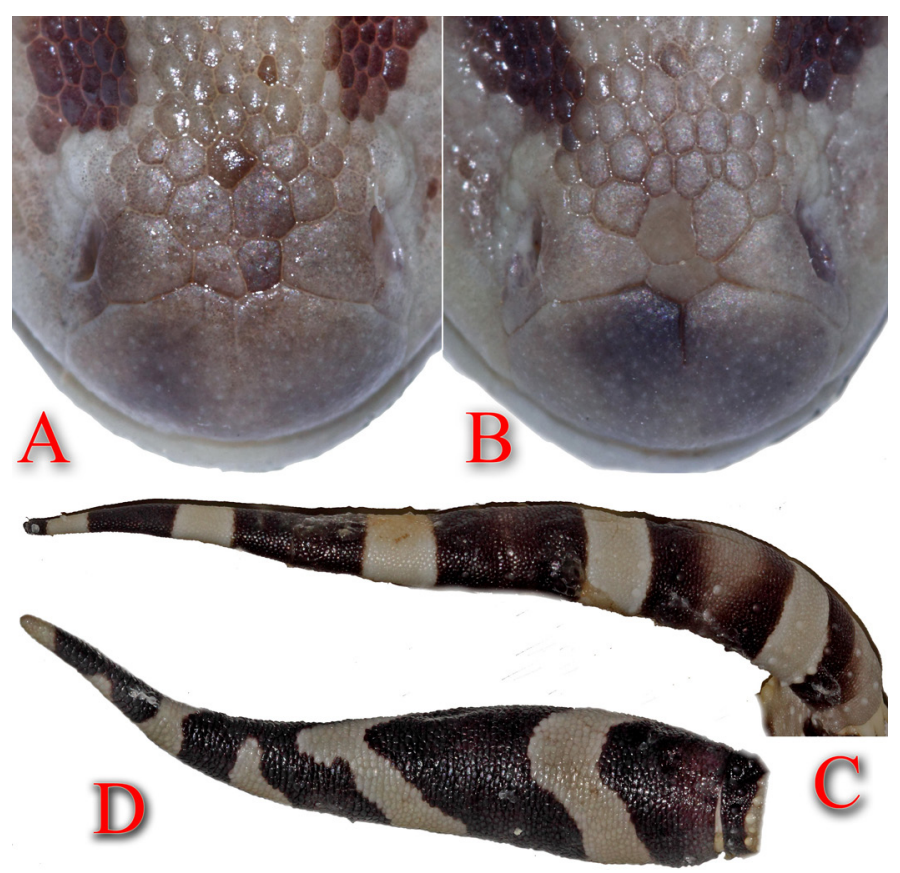

Fig. 5. Variation in internasal scales and caudal bands of Goniurosaurus araneus (KIZ-012729: A, two scales in male; C, original tail. KIZ-012730: $\mathrm{B}$, one scale in female; $\mathrm{D}$, regenerated tail). Photographs by Mian Hou.

Table 1. Measurements (mm, if applicable) of Goniurosaurus araneus specimens from Nonggang National Nature Reserve, southern Guangxi Province, China. See the text for abbreviations of characters.

\begin{tabular}{|c|c|c|}
\hline Character & $\begin{array}{c}\text { KIZ-012729 } \\
\text { male }\end{array}$ & $\begin{array}{l}\text { KIZ-012730 } \\
\text { female }\end{array}$ \\
\hline SVL & 114.89 & 108.99 \\
\hline TAL & 94.87 (original) & 67.52 (regenerated) \\
\hline SEL & 12.34 & 11.18 \\
\hline IOD & 8.76 & 8.02 \\
\hline $\mathrm{EE}$ & 9.73 & 9.55 \\
\hline HW & 21.73 & 20.96 \\
\hline $\mathrm{HH}$ & 15.34 & 14.94 \\
\hline $\mathrm{HL}$ & 35.96 & 35.05 \\
\hline FLL & 50.32 & 48.89 \\
\hline HLL & 64.65 & 55.52 \\
\hline SVL:TAL & 1.21 & 1.61 \\
\hline SVL:HL & 3.19 & 3.11 \\
\hline HL:HW & 1.65 & 1.67 \\
\hline HL:HH & 2.34 & 2.35 \\
\hline SEL:EE & 1.27 & 1.17 \\
\hline SL & $8 / 9$ & $9 / 10$ \\
\hline $\mathrm{IL}$ & $9 / 9$ & $9 / 9$ \\
\hline $\mathrm{N}$ & $7 / 6$ & $7 / 8$ \\
\hline IN & 2 & 1 \\
\hline $\mathrm{CIL}$ & $53 / 54$ & $52 / 54$ \\
\hline $\mathrm{PM}$ & 5 & 5 \\
\hline $\mathrm{GP}$ & 9 & 7 \\
\hline DTR & 22 & 21 \\
\hline GST & 11 & 11 \\
\hline $\mathrm{TL}$ & 31 & 29 \\
\hline LD1 & $9 / 10$ & $11 / 12$ \\
\hline LD2 & $15 / 17$ & $16 / 17$ \\
\hline LD3 & $19 / 18$ & $18 / 19$ \\
\hline LD4 & $19 / 20$ & $20 / 21$ \\
\hline LD5 & $11 / 16$ & $16 / 16$ \\
\hline LT1 & $9 / 11$ & $14 / 13$ \\
\hline LT2 & $18 / 18$ & $18 / 18$ \\
\hline LT3 & $24 / 23$ & $24 / 23$ \\
\hline LT4 & $25 / 24$ & $23 / 23$ \\
\hline LT5 & $21 / 21$ & $22 / 21$ \\
\hline $\mathrm{PP}$ & 23 & 0 \\
\hline PAT & $3 / 3$ & $4 / 6$ \\
\hline DT1 & 7 & regenerated \\
\hline DT4 & 5 & regenerated \\
\hline DT8 & 4 & regenerated \\
\hline
\end{tabular}




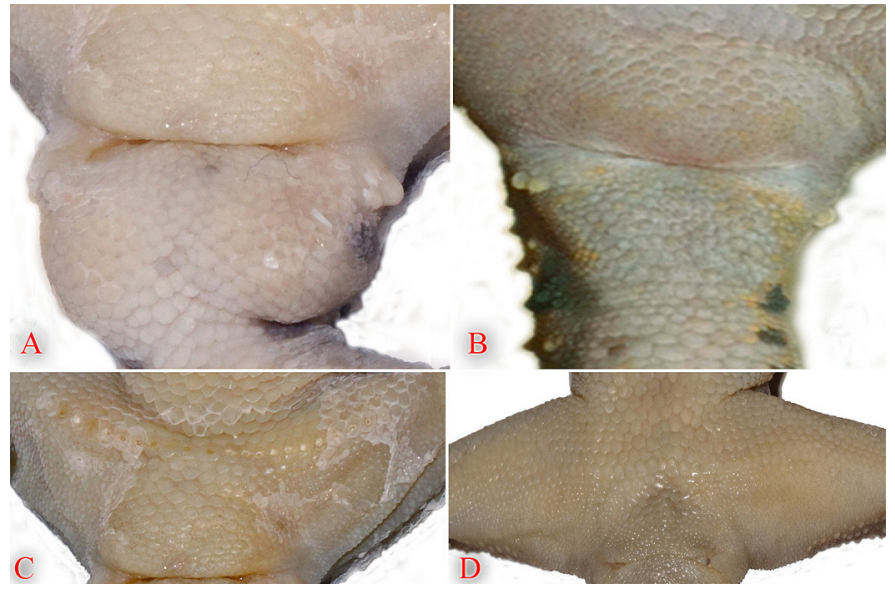

Fig. 6. Sexual dimorphism of Goniurosaurus araneus in tail base and preanal pores (male, A, C; female, B, D). Photographs by Mian Hou (KIZ012729: A, C; KIZ-012730: D) and Yi-Wu Zhu (B, pet market).

Blair et al. 2009) and G. araneus have similar counts of preanal pores, but $G$. lichtenfelderi has a larger count variation of 17-32 preanal pores (Orlov and Darevsky 1999, Grismer 2000).

With our data and those of Grismer et al. $(1999,2002)$ combined, the remaining known species from China and Vietnam all have 4-5 body bands between the forelimb insertion and caudal constriction, but $G$. araneus is the most immaculate dorsally and laterally, has the widest bright orange immaculate body bands, 5-6 white caudal bands, 6-7 nasal scales surrounding the naris, a row of enlarged supraorbital tubercles on each side, 4-6 postmentals, 52-67 eyelid fringe scales, 129-149 scales around midbody, and 23-25 subdigital lamellae under the fourth toe, its upper eyelid scales are onehalf the size of those on calvaria, and, in contrast to adults, juveniles in life are black with white body and caudal bands.

Goniurosaurus bawanglingensis (Fig. 8C) has narrower bright orange but spotted body bands, many more dark blotches on the body, a series of enlarged flat imbricate scales on the mediolateral portions of the front digital wrist, more preanal pores (37-46), but lower counts of 2-3 postmentals and 18-22 subdigital lamellae under the fourth toe, and upper eyelid scales similar in size to those on the calvaria (Grismer et al. 2002). Because of the four body bands between the forelimb insertion and caudal constriction in the photograph in Huang (1964), we could identify his specimen as close to $G$. bawanglingensis instead of a species close to $G$. lichtenfelderi, as indicated by Grismer (1988).

Goniurosaurus catbaensis (Fig. 8D) uniquely has 4-5 body bands that are narrow, orange, and immaculate, many more dark blotches on the body, fewer preanal pores (16-21), lower counts of 2-3 postmentals and 112-127 scales around midbody, and upper eyelid scales similar in size to those on the calvaria (Ziegler et al. 2008).

Goniurosaurus huuliensis (Fig. 8E) has narrower, orange, immaculate body bands, many more dark blotches on the body, particularly under the head, and lower counts of 2-3 postmentals, 41-44 eyelid fringe scales, 118-129 scales around midbody, and 18-20 subdigital lamellae under the fourth toe (Orlov et al. 2008). Although the following characters were not mentioned in Orlov et al. (2008), photographs showed that a row of enlarged supraorbital tubercles is present on each side of the orbits and the upper eyelid scales are similar in size to those on the calvaria.

Goniurosaurus liboensis (Fig. 8F) has narrower, orange, immaculate body bands, many more dark blotches on the body, a consistent number of preanal pores (23) near the lowest count for $G$. araneus, and upper eyelid scales similar in size to those on the calvaria (Wang et al. 2013).

Goniurosaurus luii (Figs. 8G-H) has narrower, bright orange, immaculate body bands, many more dark spots on the body, fewer preanal pores (18-22), and juveniles have bright orange body bands (Grismer et al. 1999, 2002). A few discrepancies exist among described characters in our observations and those of Grismer et al. $(1999,2002)$ and Wang et al. (2013). First, the row of enlarged supraorbital tubercles was supposedly absent in $G$. araneus; we found this character in both $G$. araneus and G. luii from Nonggang (Fig. 7). Second, Grismer et al. (1999) listed 61-67 eyelid fringe scales (ciliaria) in G. araneus and Wang et al. (2013; Table 4) listed 57-61 or 52-63 for G. luit; our specimens of $G$. araneus have only 52-54 and our specimens of $G$. luii only 52-58 cili-

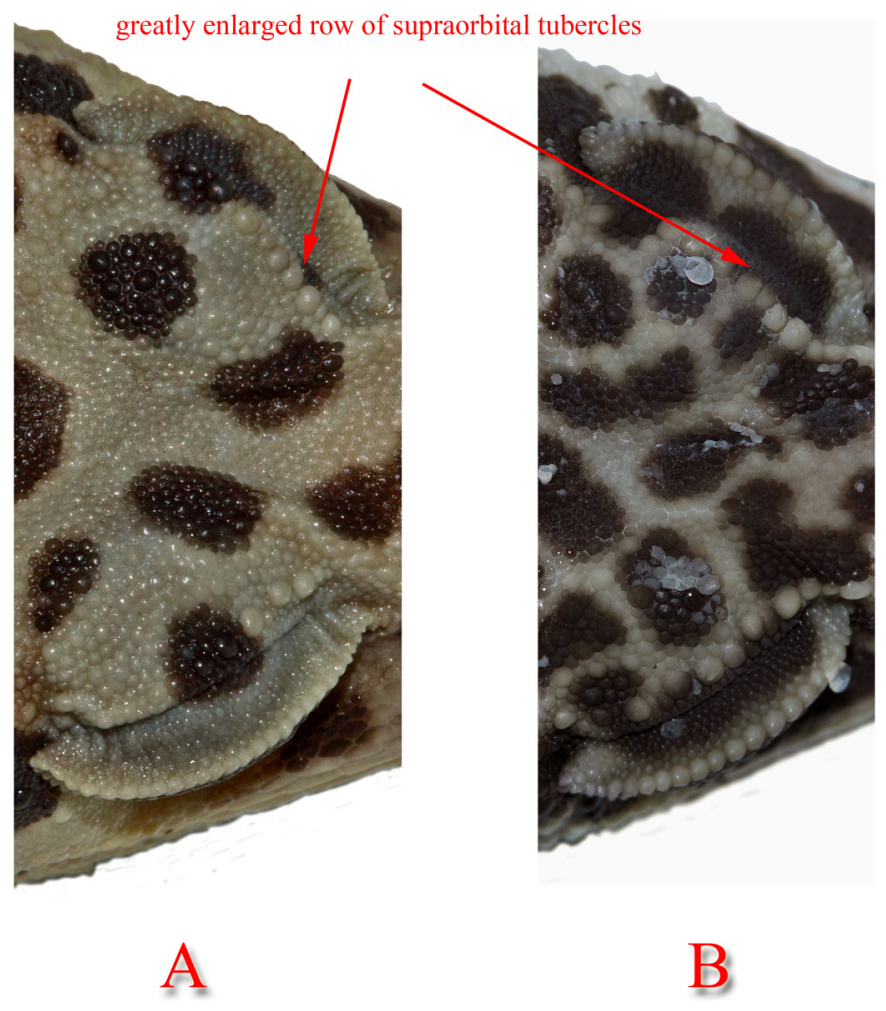

Fig. 7. A row of enlarged supraorbital tubercles in Goniurosaurus araneus (A) and G. luii (B) from Nonggang National Nature Reserve, southern Guangxi, China. Photographs by Mian Hou. 
aria, indicating that the two species overlap in this character. Among the specimens from Nonggang, we observed no obvious differences in the shapes of body scales in $G$. araneus and G. luii, whereas Grismer et al. (1999) indicated that they were more granular than elongate in $G$. araneus.

Goniurosaurus yingdeensis (Fig. 8I) has narrower, dull yellow, immaculate body bands; both males and females have relatively few preanal pores (10-13), many more dark blotches on the body, 7-10 white caudal bands, lower counts of three postmentals, 49-57 eyelid fringe scales, 107-124 scales around midbody, and 19-24 subdigital lamellae under the fourth toe, and juveniles have orange body color and yellow body bands (Wang et al. 2010, 2013). However, note that the immaculate light ring of ground body color immediately after the fourth body band on the caudal constriction was mistaken for an extra body band. That light ring is not edged by black bands anteriorly and posteriorly like the nuchal loop and body bands, and it is not present on the juvenile (Wang et al. 2010: Fig. 1B). That confirms our contention that this species has only four body bands between
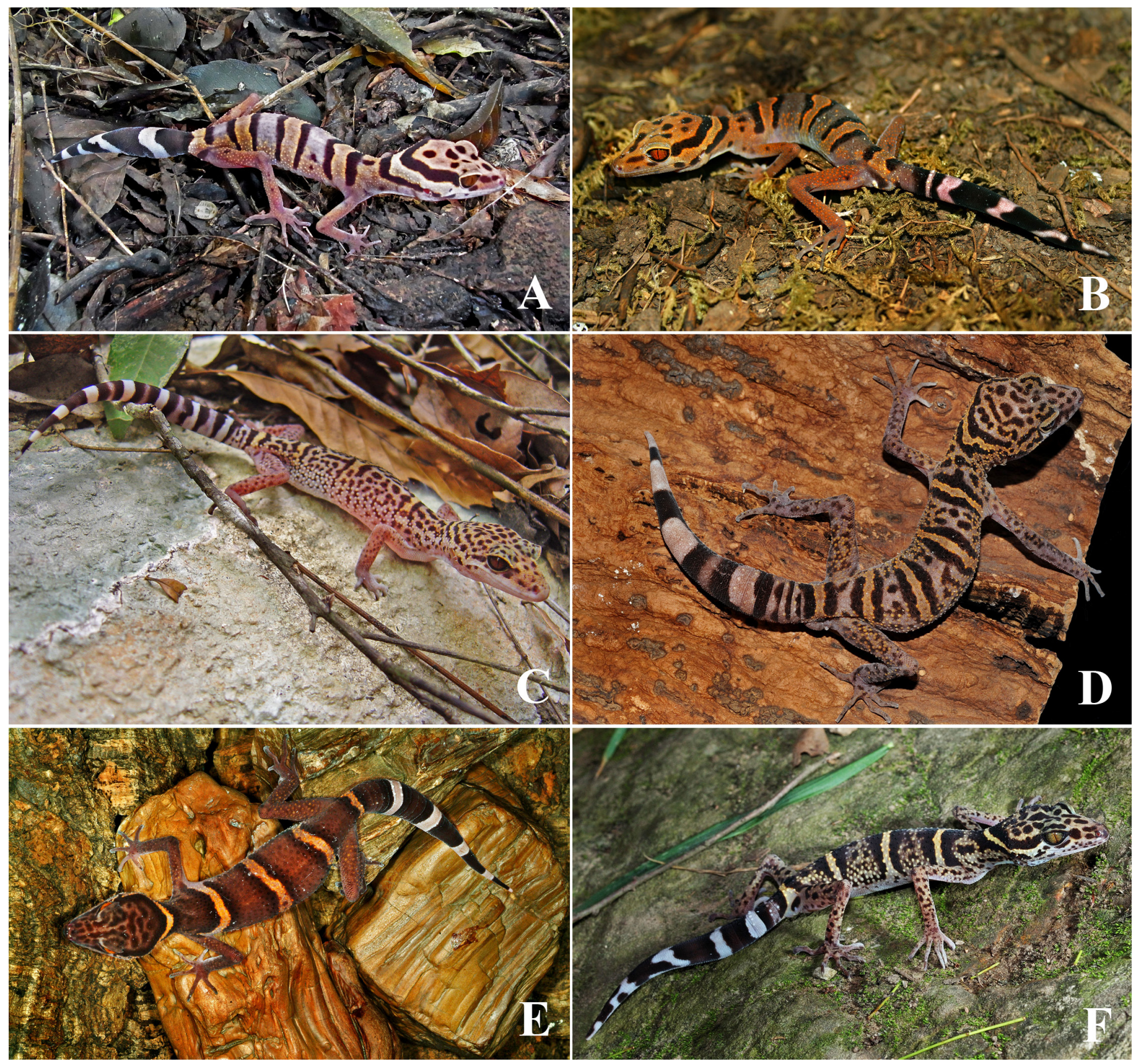

Fig. 8. Known species of Goniurosaurus from Vietnam and China in groups of $>3$ and 3 body bands between forelimb insertion and caudal constriction. A-B. G. araneus from Nonggang, Guangxi Province, China (KIZ-012730), and pet market; C. G. bawanglingensis from Bawangling National Nature Reserve (type locality), Hainan Island, China; D. G. catbaensis from Cat Ba Island (type locality), Hai Phong Province, Vietnam; E. G. huuliensis from Huu Lien Nature Reserve (type locality), Lang Son Province, Vietnam; F. G. liboensis from Libo Co. (type locality), Guizhou Province, China. 

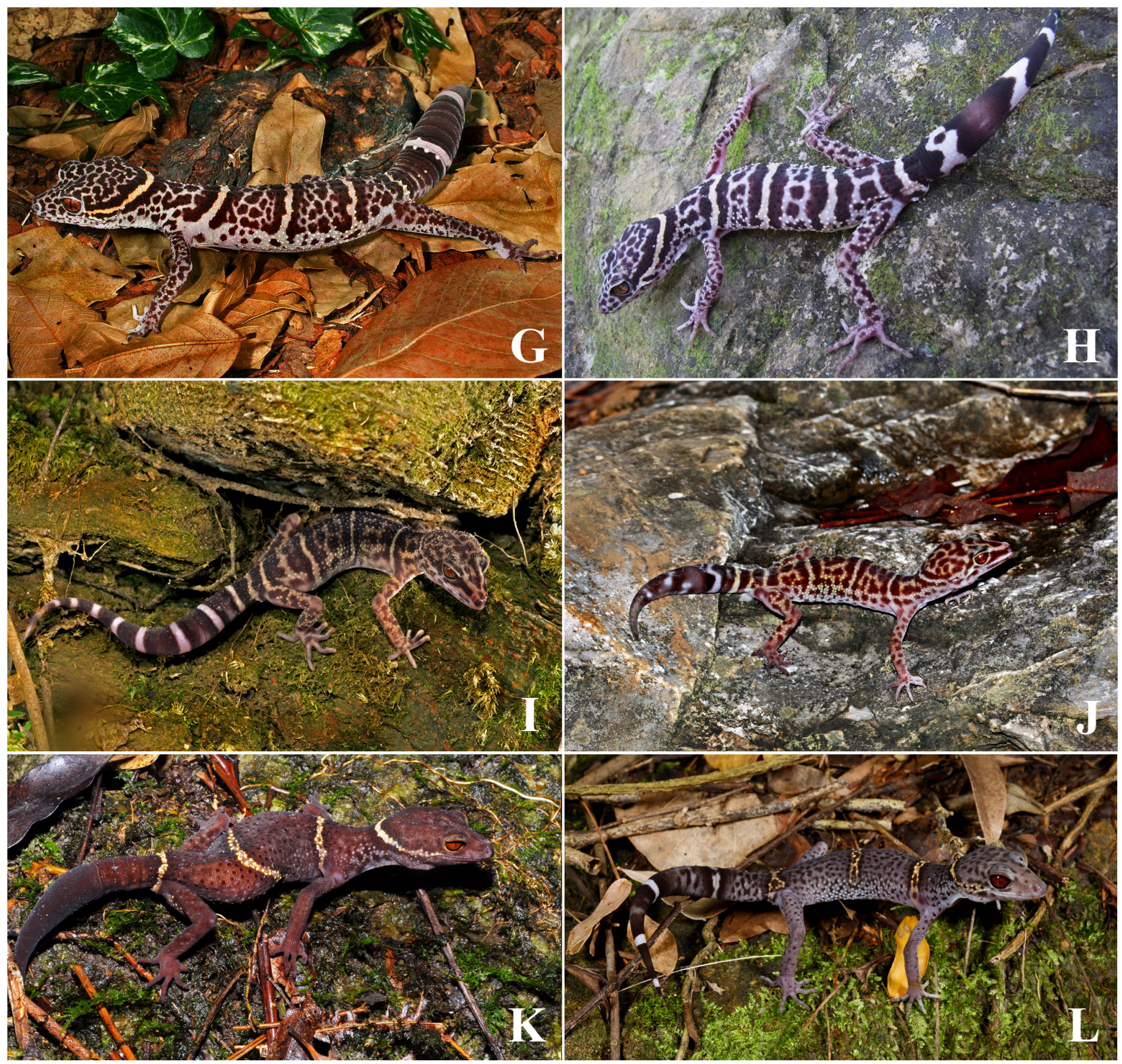

Fig. 8 (cont.). Known species of Goniurosaurus from Vietnam and China in groups of $>3$ and 3 body bands between forelimb insertion and caudal constriction. G-H. G. luii from Pingxiang Co. (type locality) and Nonggang, Guangxi Province, China; I. G. yingdeensis from Yingde Co. (type locality), Guangdong Province, China; J. Goniurosaurus indet., Qingxin Co., Guangdong Province, China; K. G. lichtenfelderi from Yen Tu Nature Reserve, Quang Ninh Province, Vietnam; L. G. hainanensis from Diaoluo Mountian, Hainan, China. Photographs by Tian-Bo Chen (A, H), Sheng Zheng (F, I, L), Nikolai L. Orlov (E, G, K), Hai-Tao Shi (C), and Mian Hou (B, J).

the forelimb insertion and the caudal constriction, not five as described by Wang et al. (2010, 2013).

Goniurosaurus indet. (Fig. 8J) has narrower, dull yellow, immaculate body bands, many more large dark blotches on the body, fewer preanal pores (12), lower counts of $2-4$ postmentals, 106-107 scales around midbody, 50-55 eyelid fringe scales, and 17-21 subdigital lamellae under the fourth toe, and juveniles have bright orange body color and yellow body bands (Yi et al. 2010). A re-examination of specimens indicated that this species has a row of enlarged supraorbital tubercles on each side and upper eyelid scales that are one-half the size of those on the calvaria; the number of caudal bands remains unknown.

\section{Discussion}

The karst area between Vietnam and Guangxi is relatively homogeneous (Ziegler et al. 2008); not only is it continuous 
but more karst species previously recorded only from northern Vietnam have been discovered in Guangxi. Currently, five species have been recorded from the karst tropical rainforest between northern Vietnam and Guangxi: G. catbaensis and $G$. huuliensis are recorded only from Vietnam and G. lichtenfelderi, $G$. luii, and herein $G$. araneus occur in both countries. High species diversity within a small area is common in Goniurosaurus, and is clearly evident, for example, in the Ryukyu Archipelago.

Of particular interest is the apparent habitat partitioning between species pairs that are closely related both geographically and phylogenetically, such as $G$. araneus and $G$. luii in southern Guangxi (Grismer et al. 1999, Kratochvil and Frynta 2002, Jonniaux and Kumazawa 2008) or G. yingdeensis and Goniurosaurus indet. from northwestern Guangdong (Zhang et al. 2014). Both pairs are separated only by a river. Seawater or rivers seem to be effective isolating barriers for geographically close populations and appear to have facilitated speciation in these Leopard Geckos. Additional cryptic species of Goniurosaurus may exist in the massive karst areas of China, particularly those farther upland that were unlikely to have been affected by historical rises and falls of sea levels. The report of G. lichtenfelderi by Wen (1983) from southern Guangxi likely represents such a cryptic species, the isolation of which probably resulted from habitat partitioning.

Although Lang Son Province in Vietnam (the location of the type locality of $G$. huuliensis) shares a common border with Guangxi, the rivers of that region do not drain into Guangxi. However, the lowland coastal area could have been contiguous into Guangxi at the foothills of Shiwandashan (which means one hundred thousand big mountains) at glacial maxima (Fig. 1). Therefore, we expect to find G. huuliensis or close relatives from neighboring Guangxi. In a similar scenario, we suspect that $G$. lichtenfelderi and $G$. hainanensis (both with three body bands between the forelimb insertion and caudal constriction) or G. catbaensis and G. huuliensis (4-5 body bands between the forelimb insertion and caudal constriction) are forms stranded on islands not long ago and represent closely related pairs.

The type locality of $G$. araneus is $40 \mathrm{~km}$ southeast of the capital of the Cao Bang Province in Vietnam (Fig. 1), which shares a common border with Guangxi Province. Nonggang NNR is on this border and thus the discovery of $G$. araneus there is not surprising. Since the species' original description (Grismer et al. 1999), no precise locality data for $G$. araneus have been published; all are listed vaguely as from Cao Bang Province, perhaps with the intent of protecting the species. The known distribution of $G$. araneus is so far limited to a small area between the Nonggang and Cao Bang border and appears to be limited to the upper tributaries that drain into the Zuojiang River (Fig. 1). We caution that the type locality of $G$. araneus might not be accurate. Subsequent efforts at that site (Orlov et al. 2008, Ziegler et al. 2008, Nguyen et al. 2009) failed to find the species, and pet market collectors tend to misstate collecting sites.

Our confirmation of the previous record of $G$. luii in Nonggang not only connects the holotypic and the northern Vietnamese populations (Fig. 1), but also supports previous evidence that $G$. araneus and $G$. luii are closely related species. However, the new records have muddied the water regarding the distribution of G. luii. Localities of the Nonggang (Yang et al. 2011) and northern Vietnamese (Thanh et al. 2006) populations are more or less within a drainage system where tributaries eventually drain into the Zuojiang River running approximately from northwest to southeast from Vietnam to Nonggang. Goniurosaurus luii and G. araneus are not sympatric, their ranges clearly separated by the Zuojiang River. Some paratypes of G. luii were from Longzhou (Grismer et al. 1999), which is also within the Nonggang NNR and in the same drainage system (these also are marked in Fig. 1). However, the holotypic locality of G. luii in Pingxiang County is in a separate drainage system. These two drainages do not meet, suggesting that the holotype was actually collected in neighboring Longzhou County instead of Pingxiang County. No one has found G. luii in Pingxiang since the species was described, although its absence there is attributed to zealous pet trade collectors (Stuart et al. 2006). The type specimens were collected for the pet trade, and localities are frequently misidentified to augment prices because customers often imagine that each locality would be represented by a different species. We cannot rule out, however, that these two drainage systems are connected underground through the porous limestone system.

Leopard Geckos are extremely popular pets. Based on our observations in China, G. araneus and G. luii have been illegally collected and extensively smuggled for some time since the original species description was published. Although only G. kuroiwae from Japan has been formally assessed as Endangered on the IUCN Red List (Ota 2010), essentially all known species of Goniurosaurus are threatened with extinction, largely due to overcollection for the international trade in live animals. Consequently, official and international efforts to protect habitat, prohibit illegal collection, and monitor the pet trade are essential.

\section{Acknowledgements}

Grants from the Global Environment Facility (2011GXGEF006), the Ministry of Science and Technology of China (2011FY120200), the National Natural Science Foundation of China (31090100), the Chinese Academy of Sciences (KSCX2EW-Z-2), the Bureau of Science and Technology of Yunnan (2010CI045), and The Conservation Agency supported this study. We are grateful to Ya-Ping Zhang and Jing Che (KIZ) for their help. Dr. Nikolai L. Orlov (Zoological Institute, Russian 
Academy of Sciences, St. Petersburg, Russia) provided some literature references and photographs. Sheng Zheng, Hang Yang, and Yi-Wu Zhu (Guangzhou Prefecture) also contributed photographs. Teppei Jono (Chengdu Institute of Biology, Sichuan, China) helped with literature on some Goniurosaurus species of the Ryukyu Archipelago.

\section{Literature Cited}

Barbour, T. 1908. Some new reptiles and amphibians. Bulletin of the Museum of Comparative Zoölogy 51:315-325.

Barbour, T. 1909. Notes on amphibia and reptilia from eastern Asia. Proceedings of the New England Zoological Club 4:53-78.

Blyth, E. 1854. Report of Curator, Zoological Department, for September 1854. Journal of the Asiatic Society of Bengal 23:729-740.

Börner, A.R. 1981. The genera of Asian eublepharine geckos and a hypothesis on their phylogeny. Miscellaneous Articles in Saurology [privately printed, Köln, Germany] 9(1):1-14.

Boulenger, G.A. 1885. Catalogue of the Lizards in the British Museum (Nat. Hist.) I. Geckonidae, Eublepharidae, Uroplatidae, Pygopodidae, Agamidae. Trustees of the British Museum, London.

Blair, C., N.L. Orlov, H.-T. Shi, and R.W. Murphy. 2009. A taxonomic re-evaluation of Goniurosaurus hainanensis (Squamata: Eublepharidae) from Hainan Island, China. Russian Journal of Herpetology 16:35-40.

Dickhoff, A. 2004. Ein Tiger im Terrarium-Haltung und Nachzucht von Goniurosaurus araneus (Grismer, Viets \& Boyle, 1999). Draco 5:76-81.

Grismer, L.L. 1987. Evidence for the resurrection of Goniurosaurus Barbour (Reptilia: Eublepharidae) with a discussion on geographic variation in Goniurosaurus lichtenfelderi. Acta Herpetologica Sinica 6:43-47.

Grismer, L.L. 1988. Phylogeny, taxonomy, classification, and biogeography of eublepharid geckos, pp. 369-469. In: R. Estes and G. Pregill (eds.), Phylogenetic Relationships of the Lizard Families. Stanford University Press, Stanford, California.

Grismer, L.L. 2000. Goniurosaurus murphyi Orlov \& Darevsky: A junior synonym of Goniurosaurus lichtenfelderi Mocquard. Journal of Herpetology 34:486-488.

Grismer L.L., H. Ota, and S. Tanaka, 1994. Phylogeny, classification, and biogeography of Goniurosaurus kuroiwae (Squamata: Eublepharidae) from the Ryukyu Archipelago, Japan, with description of a new subspecies. Zoological Science 11:319-335.

Grismer, L.L., B.E. Viets, and L.J. Boyle. 1999. Two new continental species of Goniurosaurus (Squamata: Eublepharidae) with a phylogeny and evolutionary classification of the genus. Journal of Herpetology 33:382-393.

Grismer, L.L., H.-T. Shi, N.L. Orlov, and N.B. Ananjeva. 2002. A new species of Goniurosaurus (Squamata: Eublepharidae) from Hainan Island, China. Journal of Herpetology 36:217-224.

Hu, S.-Q. and E. Zhao. 1987. Catalogue of Amphibians and Reptiles of China. Xinhua Publishing, Beijing, China (in Chinese).

Huang, Z.-J. 1964. Two new records of Chinese reptiles from Hainan - Eublepharis macularius and Typhlops diardi. Acta Zoologica Sinica 16:494-495 (in Chinese with English title).

Jonniaux, P. and Y. Kumazawa. 2008. Molecular phylogenetic and dating analyses using mitochondrial DNA sequences of Eyelid Geckos (Squamata: Eublepharidae). Gene 407:105-115.

Kratochvil, L.S. and D. Frynta. 2002. Body size, male combat and the evolution of sexual dimorphism in eublepharid geckos (Squamata: Eublepharidae). Biological Journal of the Linnaean Society 76:303-314.

Li, D.-J., J. Wang, G. Wei, D.-Z. Wang, D.-P. Li, and P. Wang. 1986. A survey of reptilians in the karst in Libo County of Guizhou Province. Acta Academiae Medicinae Zunyi 9(2):19-24 (in Chinese with English abstract).
Li, Z.-C., Z. Xiao, and S.-R. Liu. 2011. Amphibians and Reptiles of Guangdong. Guangdong Science and Technology Press, Guangzhou, China (in Chinese).

Maki, M. 1931. A new Banded Gecko, Eublepharis orientalis, sp. nov. from Riu Kyu. Annotaiones Zoologicae Japonenses 13:9-11.

Mocquard, F. 1897. Notes herpétologiques. Buletin du Muséum D'Histoirie Naturelle 3:211-217.

Namiye, M. 1912. The geckos from the Okinawa Islands. Zoological Magazine 24:442-445 (in Japanese).

Okada, Y. 1936. A new cave-gecko, Gymnodactylus yamashinae from Kumejima, Okinawa group. Proceedings of the Imperial Academy 12:53-54.

Orlov, N.L. and I.S. Darevsky. 1999. Description of a new mainland species of Goniurosaurus genus, from the north-eastern Vietnam. Russian Journal of Herpetology 6:72-78.

Orlov, N.L., S.A. Ryabov, T.T. Nguyen, Q.T. Nguyen, and T.C. Ho. 2008. A new species of Goniurosaurus (Sauria: Gekkota: Eublepharidae) from north Vietnam. Russian Journal of Herpetology 15:229-244.

Ota, H. 2010. Goniurosaurus kuroiwae. In: IUCN 2013. IUCN Red List of Threatened Species. Version 2013.2. <www.iucnredlist.org>.

Qi, Z.-Y. 1980. The tropical rain forest characteristics of Nonggang. Forest Science and Technology 1980(7):16-17 (in Chinese).

Seufer, H., Y. Kaverkin, and A. Kirschner (eds.). 2005. The genus Goniurosaurus Barbour, 1908 (Oriental Leopard Geckos), pp. 133-175. In: Die Lidgeckos. Pflege, Zucht und Lebensweise. Kirschner \& Seufer Publishing, Karlsruhe, Germany.

Smith, M.A., 1935. The Fauna of British India, Including Ceylon and Burma. Reptiles and Amphibia. Volume II. Sauria. Trustees of the British Museum, London.

Stuart, B.L., A.G.J. Rhodin, L.L. Grismer, and T. Hansell. 2006. Scientific description can imperil species. Science 312:1137.

Thanh, V.N., N.Q. Truong, L.L. Grismer, and T. Ziegler. 2006. First Record of the Chinese Leopard Gecko, Goniurosaurus luii (Reptilia: Eublepharidae) from Vietnam. Current Herpetology 25:93-95.

Wang, Y.-Y., J.-H. Yang, and R.-F. Cui. 2010. A new species of Goniurosaurus (Squamata: Eublepharidae) from Yingde, Guangdong Province, China. Herpetologica 66:208-229.

Wang, Y.-Y., J.-H. Yang, and R.-F. Cui. 2013. A new species of Goniurosaurus (Squamata: Eublepharidae) from Libo, Guizhou Province, China. Herpetologica 69:214-226.

Wen, Y.-T. 1983. Several new records of reptiles from Guangxi. Acta Herpetologica Sinica 2(3):72-74 (in Chinese).

Yang, G., D. Li, C.-X. Yu, A.-W. Jiang, Y.-J. Meng, and F. Zhou. 2011. Field survey on amphibians and reptiles in Nonggang National Nature Reserve, Guangxi. Chinese Journal of Zoology 46(4):47-52 (in Chinese with English abstract).

Yi, Z.-S., Z.-C. Li, W.-L. Wen, M. Hou, W.-H. Lu, and J. Lazell. 2010. Discovery of Goniurosaurus geckos (Squamata: Eublepharidae) in Northwestern Guangdong, China. Reptiles \& Amphibians 17:47-49.

Zhang, J., N. Qing, Z.-S. Yi, Y.-Y. Wang, X.-S. Jiang, W.-H. Lu, and J. Lazell. 2014. Validity of Goniurosaurus indet. and genetic relationships of Goniurosaurus (Squamata: Sauria: Eublepharidae) species in China. Journal of South China Normal University (Science Edition) 2014(2):92-98 (in Chinese with English abstract).

Zhao, E. and K. Adler. 1993. Herpetology of China. Contributions to Herpetology, Number 10. Society for the Study of Amphibians and Reptiles, Oxford, Ohio.

Ziegler, T., N.Q. Truong, A. Schmitz, R. Stenke, and H. Rösler. 2008. A new species of Goniurosaurus from Cat Ba Island, Hai Phong, northern Vietnam (Squamata: Eublepharidae). Zootaxa 1771:16-30. 